\title{
Nachruf für Prof. Dr. med. Dr. hc. Wilhelm Oelßner, langjähriges Ehrenmitglied der DEGRO
}

\author{
Rolf Sauer ${ }^{1}$ \\ Online publiziert: 15. Februar 2018 \\ ○) Springer-Verlag GmbH Germany, part of Springer Nature 2018
}

\section{Obituary for Prof. Dr. med. Dr. hc. Wilhelm Oelßner, longtime honorary member of DEGRO}

Am 2. Januar 2018 verstarb Herr Professor Wilhelm Oelßner, langjähriger Ordinarius für Radiologie an der Universität Leipzig, in seinem 97. Lebensjahr.

Herr Professor Oelßner wurde 1958 Direktor des Leipziger Röntgeninstituts, das er 1960 in eine radiologische Klinik umwandelte. Modellhaft und sicherlich auch deutschlandweit einmalig gab es hier weitgehend selbständige $\mathrm{Ab}-$ teilungen für Röntgendiagnostik, Strahlentherapie, Nuklearmedizin, Strahlenphysik und -technik sowie Strahlenbiologie. Die klinische und wissenschaftliche Eigenständigkeit dieser Teilgebiete war künftig nie strittig. Das hohe wissenschaftliche Ansehen des Leipziger Instituts spiegelte sich u. a. darin wieder, dass sich hier 18 Wissenschaftler habilitierten, von denen fünf in Ostdeutschland auf Lehrstühle berufen wurden.

Oelßners starker Charakter und seine große Persönlichkeit machten ihn in zahlreichen Gremien, Kommissionen und Fachgesellschaften unentbehrlich: Von 1961 bis 1965 war er Vorsitzender der Gesellschaft für medizinische Radiologie der DDR, wissenschaftlicher Leiter der Kongresse dieser Gesellschaft in den Jahren 1962, 1963 und 1965, Vorsitzender der Gesellschaft für Geschwulstbekämpfung von
1973 bis 1975, Ehrenmitglied der tschechoslowakischen radiologischen Gesellschaft und der deutschen Röntgengesellschaft. Seit 1975 war Professor Oelßner ordentliches Mitglied der sächsischen Akademie der Wissenschaften zu Leipzig. Nach der friedlichen Revolution trug er als Vorsitzender der Ehrenkommission wesentlich dazu bei, der Akademie eine neue Orientierung zu geben und sie von Belastungen aus der Vergangenheit zu befreien.

Seit 1978 war Oelßner Mitglied der deutschen Akademie der Naturforscher Leopoldina, der ältesten, ununterbrochen bestehenden Gelehrtenvereinigung der Welt. Im Jahr 1987 wurde er Ehrensenator der Leipziger Universität, die ihn darüber hinaus 1995 mit der Ehrendoktorwürde ehrte. Die sächsische radiologische Gesellschaft verlieh ihm den Baensch-Preis und die deutsche Gesellschaft für Radioonkologie machte ihn 1997 auf ihrem Jahreskongress in Leipzig (Kongresspräsident Prof. Dr. Friedrich Kamprad) zu ihrem Ehrenmitglied.

Die Deutsche Gesellschaft für Radioonkologie wird sein Andenken in Ehren halten.

Rolf Sauer, Erlangen

Prof. Dr. Rolf Sauer

Rolf.Sauer@t-online.de

191054 Erlangen, Deutschland 